\title{
Phantoms for Development of Microwave Sensors for Noninvasive Blood Glucose Monitoring
}

\author{
Jan Vrba, Jakub Karch, and David Vrba \\ Department of Biomedical Technology, Faculty of Biomedical Engineering, Czech Technical University in Prague, \\ Zikova 4, 16636 Prague, Czech Republic
}

Correspondence should be addressed to Jan Vrba; jan.vrba@fbmi.cvut.cz

Received 24 November 2014; Revised 16 January 2015; Accepted 20 January 2015

Academic Editor: Chih-Hua Chang

Copyright (C) 2015 Jan Vrba et al. This is an open access article distributed under the Creative Commons Attribution License, which permits unrestricted use, distribution, and reproduction in any medium, provided the original work is properly cited.

A suitability of two different liquid phantoms of blood-glucose solutions as phantoms for development of microwave sensors for noninvasive blood glucose monitoring is compared. The two phantoms are physiological saline-glucose and pig blood-glucose solutions. For this purpose a simple microwave sensor is developed for in vitro monitoring of blood glucose levels. The sensor consists of a microstrip antenna and of a small rectangular container on the top of the antenna. The container is filled with one of the liquid phantoms. Both phantoms with different glucose concentrations ranging from 0 to $500 \mathrm{mg} / \mathrm{dL}$ are considered. Dependence of sensor's resonant frequency on glucose concentration of LUTs is both estimated by aid of numerical simulations and measured. The results are discussed and compared with some results reported in the literature.

\section{Introduction}

In 2014, 382 million people ( $8.3 \%$ of the overall population) have diabetes and it is expected that up to year 2035 the number of people with diabetes will rise to 592 million. More than $11 \%$ of healthcare spending worldwide is on treatment of diabetes [1]. Current techniques for blood glucose monitoring are all invasive associated with number of obvious inconveniences. Regular blood glucose monitoring by diabetes patients would both significantly improve their quality of life and decrease the diabetes-treatment cost. Therefore, there is a clear demand for an inexpensive noninvasive blood glucose monitoring technique.

There are already a number of research groups and companies developing noninvasive blood glucose monitoring systems [2-5]. The company MediWiSe announced start of preorders for their microwave device in late 2016.

With respect to development of an electromagnetic noninvasive glucose monitoring system some authors report dielectric properties of physiological saline-glucose [6] and of blood plasma-glucose solutions $[7,8]$. In $[9,10]$, it has been shown that glucose influences dielectric properties of blood significantly, but an analytical model has not been published there. To authors' best knowledge the only paper publishing mathematical model of dielectric properties of blood-glucose solutions is [11]. In [12], the authors measured dielectric properties of blood-glucose solutions but mathematical model has not been published. One of the main aims of this paper is to show, both by numerical simulation results and by measurement results, that there are significant differences between dielectric properties of physiological saline-glucose and blood-glucose solutions. Correspondingly, the physiological saline-glucose solutions are, at least in the considered frequency range, not suitable models of blood-glucose solutions for experimental design/evaluation of blood glucose level monitoring systems.

In this paper, a simple microwave sensor based on microstrip (MS) patch antenna principles is developed for in vitro blood glucose level monitoring. The MS patch antenna has been chosen here because it is flat and even though the present study is performed for in vitro experiments, only the geometry of the sensor could be with small changes used for in vivo experiments as well. The preliminary antenna dimensions were calculated with well-known design rules [13]. The sensor consists, besides of the antenna, of a small container filled with LUT. The sensor was modeled and fine-tuned, in 
order to obtain low reflection coefficient at the resonant frequency, in COMSOL Multiphysics [14]. For both numerical simulations and measurements two LUTs were considered, physiological saline-glucose and blood-glucose solutions, with different glucose concentrations. For both LUTs the first resonant frequency of the sensor (with filled container) lies at about $2 \mathrm{GHz}$. The sensor was manufactured and the shift of the resonant frequency of the antenna was both measured and simulated for both considered glucose solutions.

\section{LUTs: Models of Their Dielectric Properties and Preparation}

The glucose concentrations in LUTs were chosen, both physiological and nonphysiological concentrations. The nonphysiological concentrations considered here are still realistic as they can be reached by diabetes patients.

For numerical design and evaluation of the sensor, mathematical models of dielectric properties of physiological saline-glucose and blood-glucose solutions were adopted from [15] and [11], respectively. It has to be noted that the model from [11] is based on measurements using the commercial system Dielectric Probe Kit with the Slim Probe, both from the company Keysight Technologies (formerly Agilent) [16]. Since it is difficult to use this equipment for the liquids with inhomogeneous surface (blood samples have such surface), the measured data are correspondingly negatively influenced. Nevertheless, to the authors' best knowledge, there is no other mathematical model for blood-glucose solutions dielectric properties.

Both models were implemented in MATLAB [17] and imported into COMSOL Multiphysics numerical model of the sensor (Figure 1). The numerical model of the sensor was subsequently used for sensor optimization as well as for further numerical investigations performed here.

Physiological saline-glucose solutions were prepared by addition of an amount of D-glucose, according to Table 1, into $0.5 \mathrm{~L}$ of physiological saline. The pig blood samples were taken in a slaughterhouse by slaughterhouse employees into $9 \mathrm{~mL}$ test tubes with K3 EDTA (anticlotting agent). Except for a reference sample with reference value of glucose, three other samples were prepared in $25 \mathrm{~mL}$ volumetric flasks by adding an amount of D-glucose, according to Table 2, into $25 \mathrm{~mL}$ of pig blood. The obtained four samples had the following glucose concentrations: reference value, reference value $+125 \mathrm{mg} / \mathrm{dL}$, reference value $+250 \mathrm{mg} / \mathrm{dL}$, and reference value $+500 \mathrm{gm} / \mathrm{dL}$.

\section{Sensor Design, Numerical Model, Realization, and Measurement}

As already mentioned, the microwave sensor is based on the MS patch antenna. The preliminary antenna dimensions were calculated using well-known design rules [13] in such a way the antenna resonates (with the empty container) at $5 \mathrm{GHz}$. The antenna layout is shown in Figure 2 and the dimensions are as follows. The substrate is FR4 with substrate

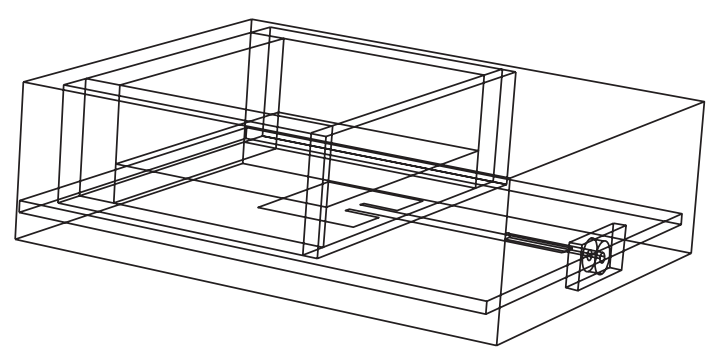

FIgURE 1: Numerical model of sensor geometry in COMSOL Multiphysics.

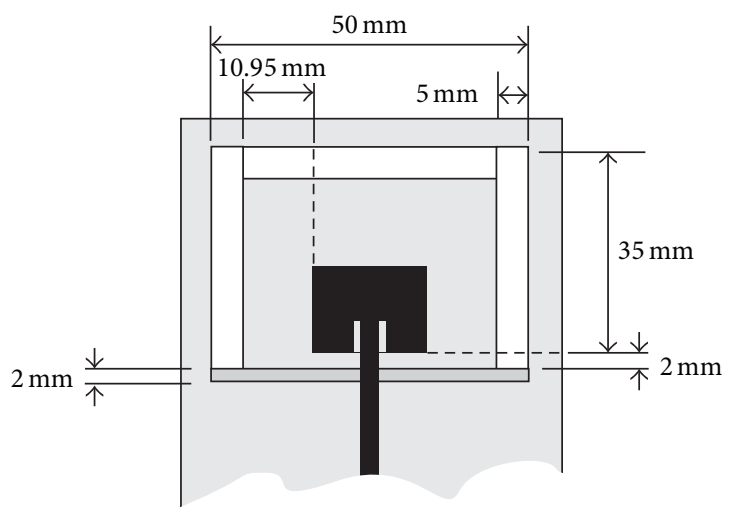

FIGURE 2: Simplified technical drawing of the container (top view). Lucite (upper and side walls) and PTFE (lower wall). Container height is $3 \mathrm{~cm}$.

TABLE 1: Weighing of D-glucose for sample preparation of physiological saline-glucose solutions.

\begin{tabular}{lcc}
\hline $\begin{array}{l}\text { Desired } \\
\text { concentration } \\
(\mathrm{mg} / \mathrm{dL})\end{array}$ & $\begin{array}{c}\text { Weighing for 0,5 L } \\
(\mathrm{mg})\end{array}$ & $\begin{array}{c}\text { Measured } \\
\text { concentration } \\
(\mathrm{mg} / \mathrm{dL})\end{array}$ \\
\hline 250 & 1268,5 & 253,8 \\
500 & 2512,3 & 502,5 \\
1000 & 5008,2 & 1001,6 \\
\hline
\end{tabular}

TABLE 2: Weighing of D-glucose for sample preparation of pig blood-glucose solutions.

\begin{tabular}{lcc}
\hline $\begin{array}{l}\text { Desired } \\
\text { concentration } \\
(\mathrm{mg} / \mathrm{dL})\end{array}$ & $\begin{array}{c}\text { Weighing for } 25 \mathrm{~mL} \\
(\mathrm{mg})\end{array}$ & $\begin{array}{c}\text { Measured } \\
\text { concentration } \\
(\mathrm{mg} / \mathrm{dL})\end{array}$ \\
\hline 125 & 34,92 & 139,8 \\
250 & 79,23 & 316,9 \\
500 & 133,73 & 534,9 \\
\hline
\end{tabular}

height equal to $1.5 \mathrm{~mm}$. The width of feeding MS transmission line is equal to $2.8 \mathrm{~mm}$. SMA panel connector was used. Patch width and length are equal to $18.1 \mathrm{~mm}$ and $13.6 \mathrm{~mm}$, respectively. The container dimensions from the top view are shown in Figure 2 and its height is equal to $30 \mathrm{~mm}$. Side walls of the container are made from PTFE and Lucite according to Figure 2. Filling the container with LUT shifts resonant 


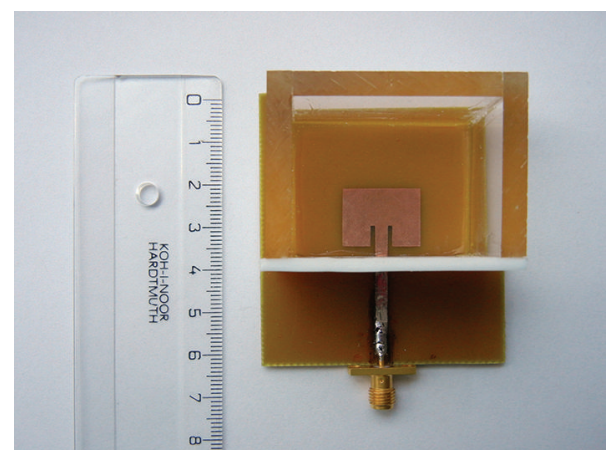

FIGURE 3: Photograph of the realized microwave sensor (top view).

frequency of the sensor to about $2 \mathrm{GHz}$ (depends on used LUT and its glucose concentration). The sensor was first numerically modeled and subsequently fine-tuned (in terms of low reflection coefficient at the resonant frequency) in COMSOL Multiphysics.

The final antenna was manufactured using standard etching process and the side walls of the container were glued to the top of the antenna. The manufactured sensor with the empty container is shown in Figure 3.

Measurement of reflection coefficient has been performed using vector network analyzer Rohde \& Schwarz FSH8.28 calibrated as full one-port calibration with ZV-Z170 Calibration Kit 50.

For physiological saline-glucose solutions in total 27 independent (after each measurement the LUT was removed from the container and the container was cleaned) measurements were performed. Six measurements were performed for each sample except for $250 \mathrm{mg} / \mathrm{dL}$, where five measurements were performed only.

For reference sample (without added glucose) of pig blood five independent measurements were performed. Three pig blood samples with different glucose amount added were measured as well. In total 8 independent measurements were performed for pig blood samples.

\section{Numerical and Measurement Results and Discussion}

By a simple comparison of dielectric properties of both LUTs it is clear that the same change in glucose concentration produces bigger changes of the dielectric properties of bloodglucose solution than of physiological saline-glucose solution. The magnitudes of reflection coefficients of the sensor depending on frequency, LUT, and different glucose concentrations were simulated and are plotted in Figures 4 and 5. The numerical results confirm the above-mentioned statement. The glucose concentrations chosen for the numerical simulations were 0,125 , and $250 \mathrm{mg} / \mathrm{dL}$. By the physiological saline-glucose solutions the resonant frequency shifts about $5 \mathrm{MHz}$ if glucose concentration changes from 0 to 125 or from 125 to $250 \mathrm{mg} / \mathrm{dL}$. By the blood-glucose solutions there are

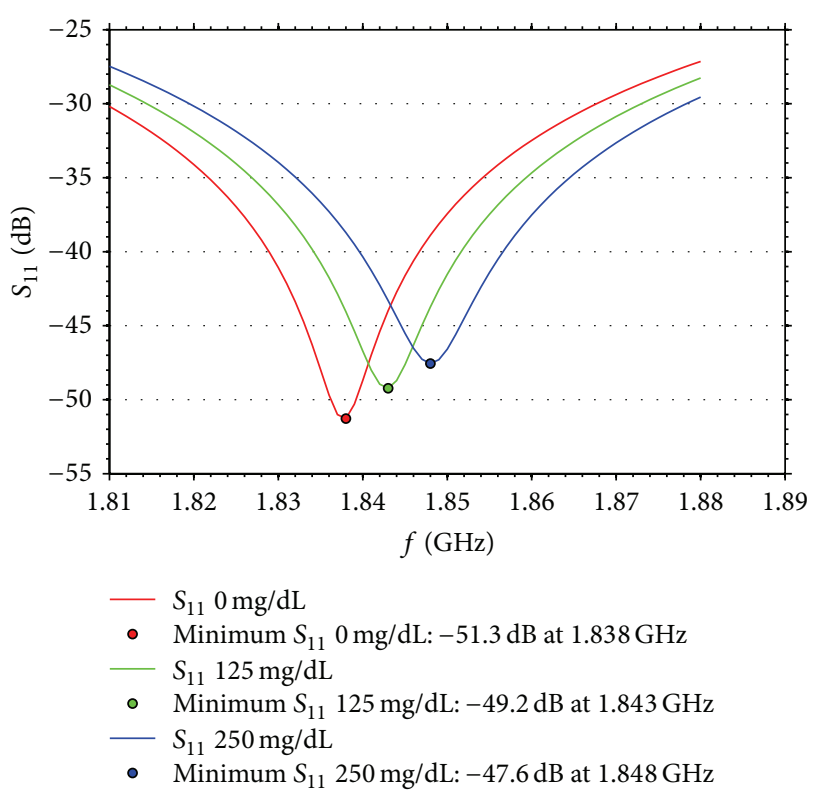

FIGURE 4: Computed $S_{11}$ of the sensor with container virtually filled with physiological saline [15] with different glucose concentrations.

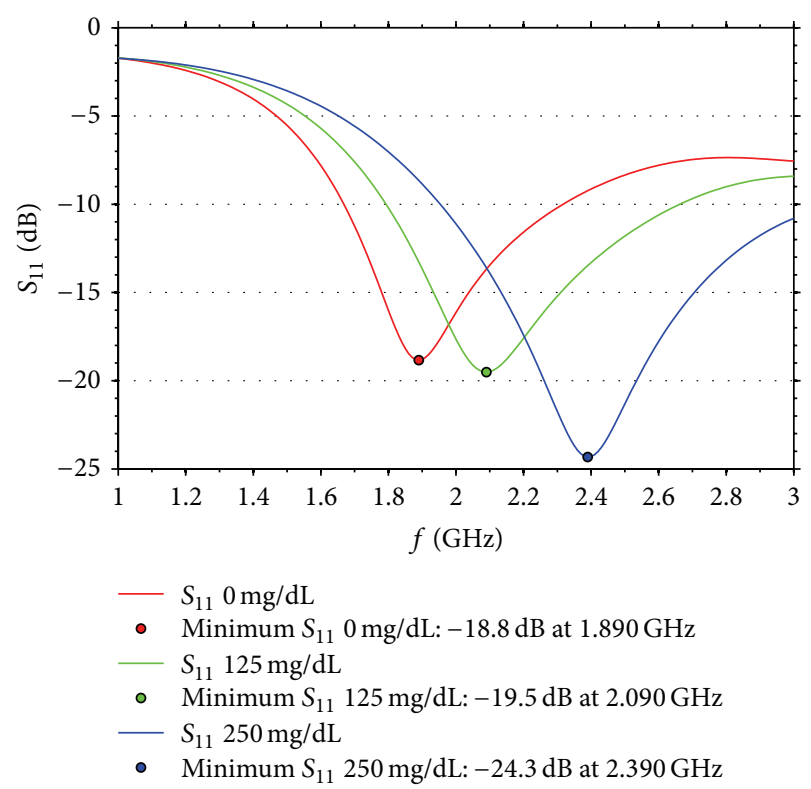

FIGURE 5: Computed $S_{11}$ of the sensor with container virtually filled with blood [11] with different glucose concentrations.

much bigger resonant frequency shifts. If glucose concentration changes from 0 to $125 \mathrm{mg} / \mathrm{dL}$ and from 125 to $250 \mathrm{mg} / \mathrm{dL}$ the frequency shifts 200 and $300 \mathrm{MHz}$, respectively.

The measurements were performed at the room temperature $\left(23^{\circ} \mathrm{C}\right)$. The goal was to just investigate whether the shifts of the sensor's resonant frequency depending on glucose concentration are comparable with those numerically simulated and whether they are sufficient for estimation of the glucose concentration in LUT. 


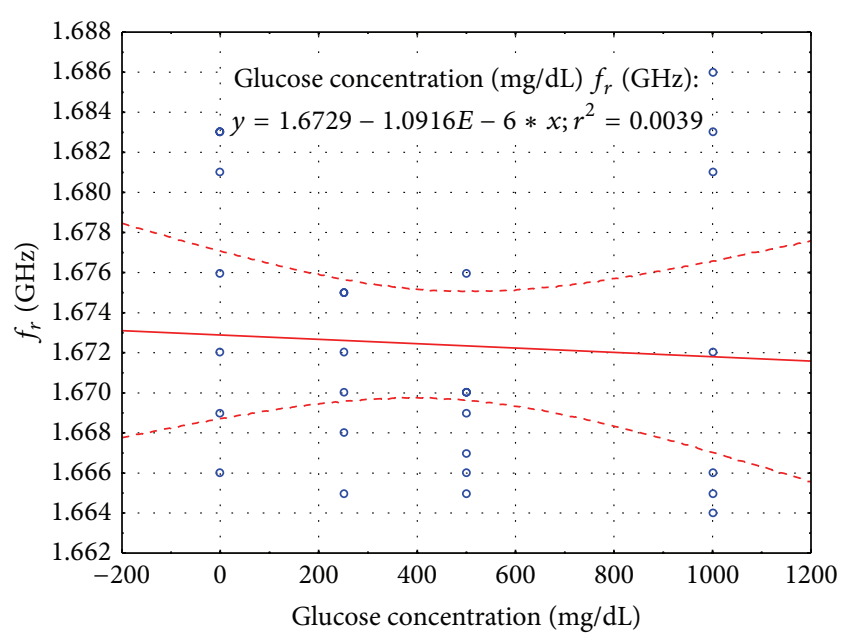

FIGURE 6: Dependence of sensor resonant frequencies on glucose concentration of physiological saline-glucose solutions; dashed red lines denote $95 \%$ confidence interval.

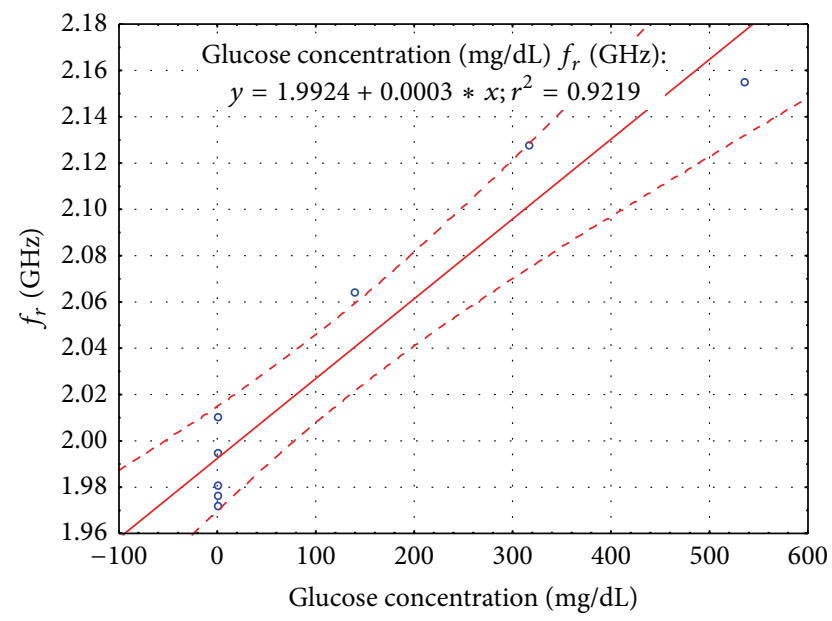

FIGURE 7: Dependence of sensor resonant frequencies on glucose concentration of pig blood-glucose solutions; dashed red lines denote $95 \%$ confidence interval.

Figures 6 and 7 show measured sensor resonant frequencies dependent on LUT and glucose concentration. For the physiological saline-glucose solutions (Figure 6) there is no statistically evident relation between the glucose concentration and resonant frequency. This is consistent with the fact that already for $0 \mathrm{mg} / \mathrm{dL}$ glucose concentration and 6 independent measurements the measured resonant frequencies lie in an interval between 1.666 and $1.682 \mathrm{GHz}$. This shift is even bigger than the predicted shift for glucose concentration change from 0 to $250 \mathrm{mg} / \mathrm{dL}$. Probably minimal temperature and/or volume change of LUT produced bigger change of resonant frequency than the change in glucose concentration. On the other hand, the trend shown in Figure 7 for pig blood-glucose solutions is clear. The shifts of sensor resonant frequencies corresponding to change in glucose concentration between reference value and reference value +125 , reference value +125 and reference value +250 , and reference value +250 and reference value $+500 \mathrm{mg} / \mathrm{dL}$ are 43 , 43 , and $86 \mathrm{MHz}$, respectively.

There is also a significant difference, by a factor of 4.7 to 7 , between measured and simulated changes of resonance frequency.

In [11], a different microwave sensor for in vitro measurements of blood glucose concentrations was developed and tested. Measurements of frequency shift of the sensor were performed and reported resonant frequency shift was approximately $125 \mathrm{MHz}$ for glucose concentration changes from 91 to $330 \mathrm{mg} / \mathrm{dL}$. If a linear dependence is considered, this would lead to a slope of $65 \mathrm{MHz}$ for $125 \mathrm{mg} / \mathrm{dL}$ concentration change. The difference between the resonant frequency shift reported in [11] and here is only by a factor of $65 / 43=$ 1.5. It has to be noted that our measurements were performed at the room temperature while the measurements reported in [11] were performed at $37^{\circ} \mathrm{C}$. Another explanation could be that the considered sensors have different sensitivity.

Even though a difference of factor 1.5 is not satisfactory, it is much better than a factor of 4.7-7. This is an indication that mathematical model of dielectric properties of bloodglucose solutions reported in [11] should be improved by repeating the measurements presented there. Also we can conclude that physiological saline-glucose solutions are not a suitable model of blood for the purpose of development of noninvasive blood glucose monitoring system.

\section{Conclusions and Outlook}

In this paper, a microwave sensor for in vitro blood glucose level monitoring was designed, manufactured, and tested using two LUTs with different glucose concentrations, namely, physiological saline-glucose and pig blood-glucose solutions. Resonant frequency shifts of the sensor depending on LUT and its glucose concentrations were simulated and measured. No trend of shifts of resonant frequencies for physiological saline-glucose solutions was detected by measurements. The shifts are probably masked by shifts caused by small changes of dielectric properties of LUT due to small changes of room temperature. The shifts of resonant frequencies for pig blood-glucose solutions showed clear linear trend with a slope which could be used for estimation of glucose level. Based on the results obtained in this paper it can be concluded that the physiological saline-glucose solutions are, at least in the considered frequency range, not suitable models of blood-glucose solutions for experimental design/evaluation of blood glucose level monitoring systems.

The sensor presented in this paper has not been optimized in terms of sensitivity. Furthermore, it is not small enough for a noninvasive in vivo measurement. Such sensor should fit in an earlobe or could be placed above one of the arteries, for example, on wrist, on temple, and behind the knee. Currently we develop a microwave sensor based on electrically small antenna utilizing zero-order resonance similar to those presented in [18]. Such sensor can be scaled almost arbitrarily to fit the desired area. The field irradiated by the sensor shows in the plane under its aperture very homogeneous pattern and decays almost as an EM plane wave in given media. 
Sensor sensitivity could be improved considering techniques reviewed, for example, in [19].

\section{Conflict of Interests}

The authors declare that there is no conflict of interests regarding the publication of this paper.

\section{Acknowledgment}

This research has been supported by the Czech Scientific Foundation, Project no. 14-00386P, Study of Thermal and Nonthermal Effects of High-Power EM Field on Structure of Matter.

\section{References}

[1] International Diabetes Federeation, IDF Diabetes Atlas, 6th edition, 2013, http://www.idf.org/diabetesatlas.

[2] C.-F. So, K.-S. Choi, T. K. S. Wong, and J. W. Y. Chung, "Recent advances in noninvasive glucose monitoring," Medical Devices, vol. 5, no. 1, pp. 45-52, 2012.

[3] B. R. Jean, E. C. Green, and M. J. McClung, "A microwave frequency sensor for non-invasive blood-glucose measurement," in Proceedings of the 3rd IEEE Sensors Applications Symposium (SAS '08), pp. 4-7, February 2008.

[4] E. C. Green, Design of a microwave sensor for non-invasive determination of blood-glucose concentration [Ph.D. thesis], 2005, Includes bibliographical references (p. 53-56).

[5] B. Freer and J. Venkataraman, "Feasibility study for noninvasive blood glucose monitoring," in Proceedings of the IEEE Antennas and Propagation Society International Symposium (APSURSI '10), pp. 1-4, IEEE, Toronto, Canada, July 2010.

[6] P. F. M. Smulders, M. G. Buysse, and M. D. Huang, "Dielectric properties of glucose solutions in the $0.5-67 \mathrm{GHz}$ range," Microwave and Optical Technology Letters, vol. 55, no. 8, pp. 1916-1917, 2013.

[7] E. Topsakal, T. Karacolak, and E. Moreland, "Glucose-dependent dielectric properties of blood plasma," in Proceedings of the 30th General Assembly and Scientific Symposium, pp. 1-4, IEEE, Istanbul, Turkey, August 2011.

[8] T. Karacolak, E. C. Moreland, and E. Topsakal, "Cole-cole model for glucose-dependent dielectric properties of blood plasma for continuous glucose monitoring," Microwave and Optical Technology Letters, vol. 55, no. 5, pp. 1160-1164, 2013.

[9] Y. Hayashi, L. Livshits, A. Caduff, and Y. Feldman, "Dielectric spectroscopy study of specific glucose influence on human erythrocyte membranes," Journal of Physics D: Applied Physics, vol. 36, no. 4, pp. 369-374, 2003.

[10] L. Livshits, A. Caduff, M. S. Talary, and Y. Feldman, "Dielectric response of biconcave erythrocyte membranes to D- and LGlucose," Journal of Physics D: Applied Physics, vol. 40, no. 1, pp. 15-19, 2007.

[11] J. Venkataraman and B. Freer, "Feasibility of non-invasive blood glucose monitoring: in-vitro measurements and phantom models," in Proceedings of the IEEE International Symposium on Antennas and Propagation (APSURSI '11), pp. 603-606, July 2011.

[12] M. Hofmann, G. Fischer, R. Weigel, and D. Kissinger, "Microwave-based noninvasive concentration measurements for biomedical applications," IEEE Transactions on Microwave Theory and Techniques, vol. 61, no. 5, pp. 2195-2204, 2013.

[13] C. Balanis, Antenna Theory: Analysis and Design, John Wiley \& Sons, New York, NY, USA, 2nd edition, 1997.

[14] COMSOL AB, COMSOL Multiphysics User's Guide, Version 4.3, 2012.

[15] J. Karch, Dielectric-properties measurements of glucose solutions and design of suitable measurement probe for noninvasive monitoring of blood glucose levels [M.S. thesis], Faculty of Biomedical Engineering, Czech Technical University in Prague, Prague, Czech Republic, 2014.

[16] Keysight Technologies, "Keysight 85070E dielectric probe kit, $200 \mathrm{MHz}$ to $50 \mathrm{GHz}$," Technical Overview, Keysight Technologies, Santa Clara, Calif, USA, 2014.

[17] Matlab 7, Program and User's Manual, 2010.

[18] D. Vrba and J. Vrba, "Novel applicators for local microwave hyperthermia based on zeroth-order mode resonator metamaterial," International Journal of Antennas and Propagation, vol. 2014, Article ID 631398, 7 pages, 2014.

[19] J. J. Yang, M. Huang, H. Tang, J. Zeng, and L. Dong, "Metamaterial sensors," International Journal of Antennas and Propagation, vol. 2013, Article ID 637270, 16 pages, 2013. 

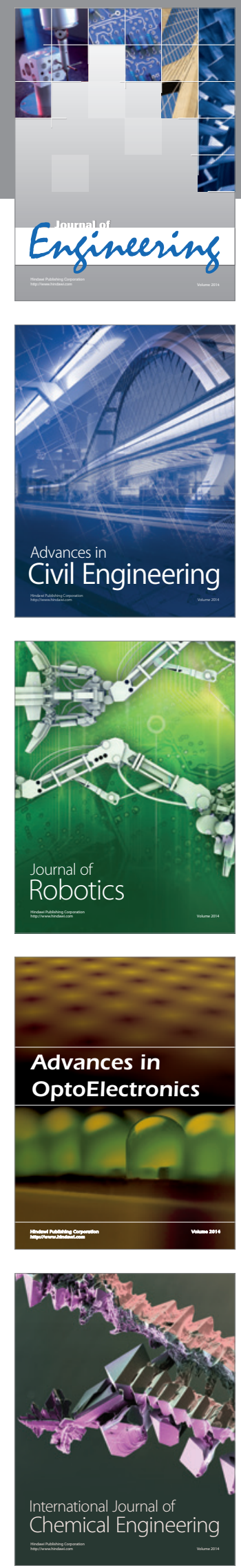

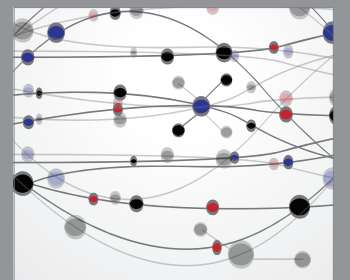

The Scientific World Journal
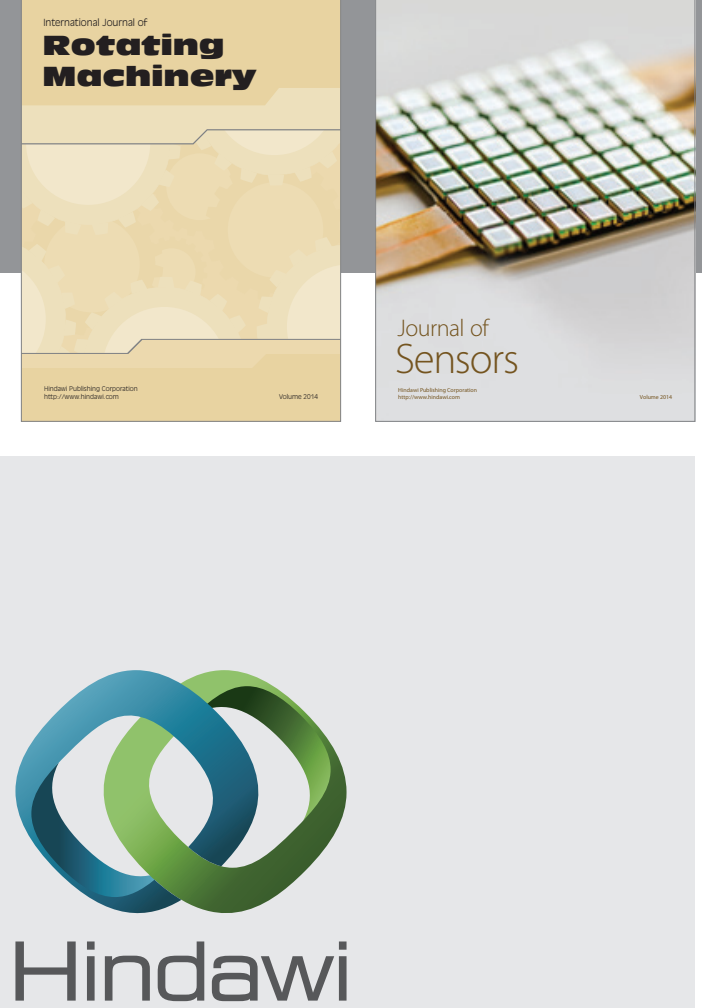

Submit your manuscripts at http://www.hindawi.com
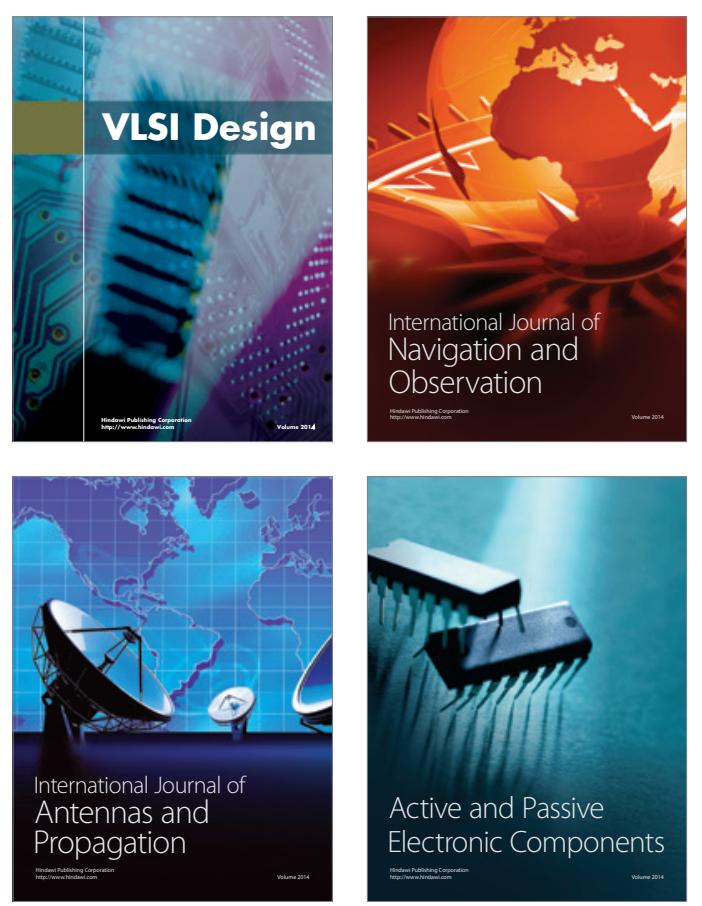
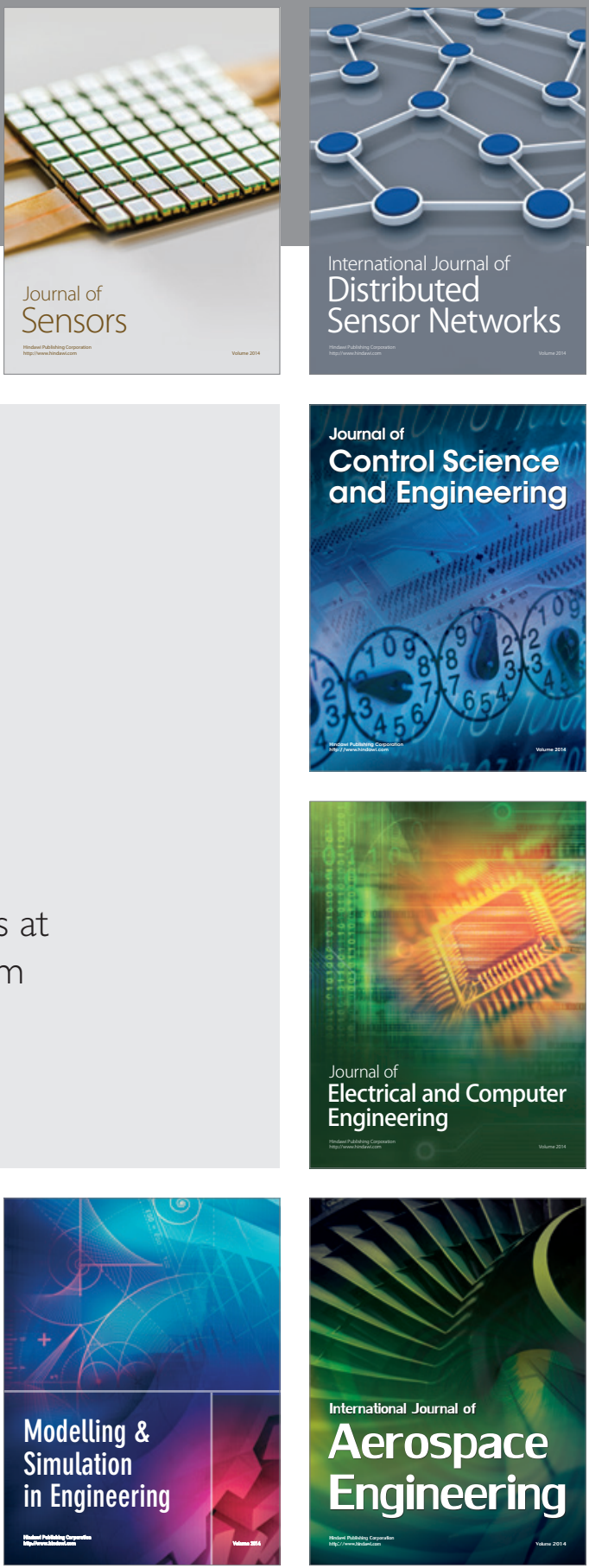

Journal of

Control Science

and Engineering
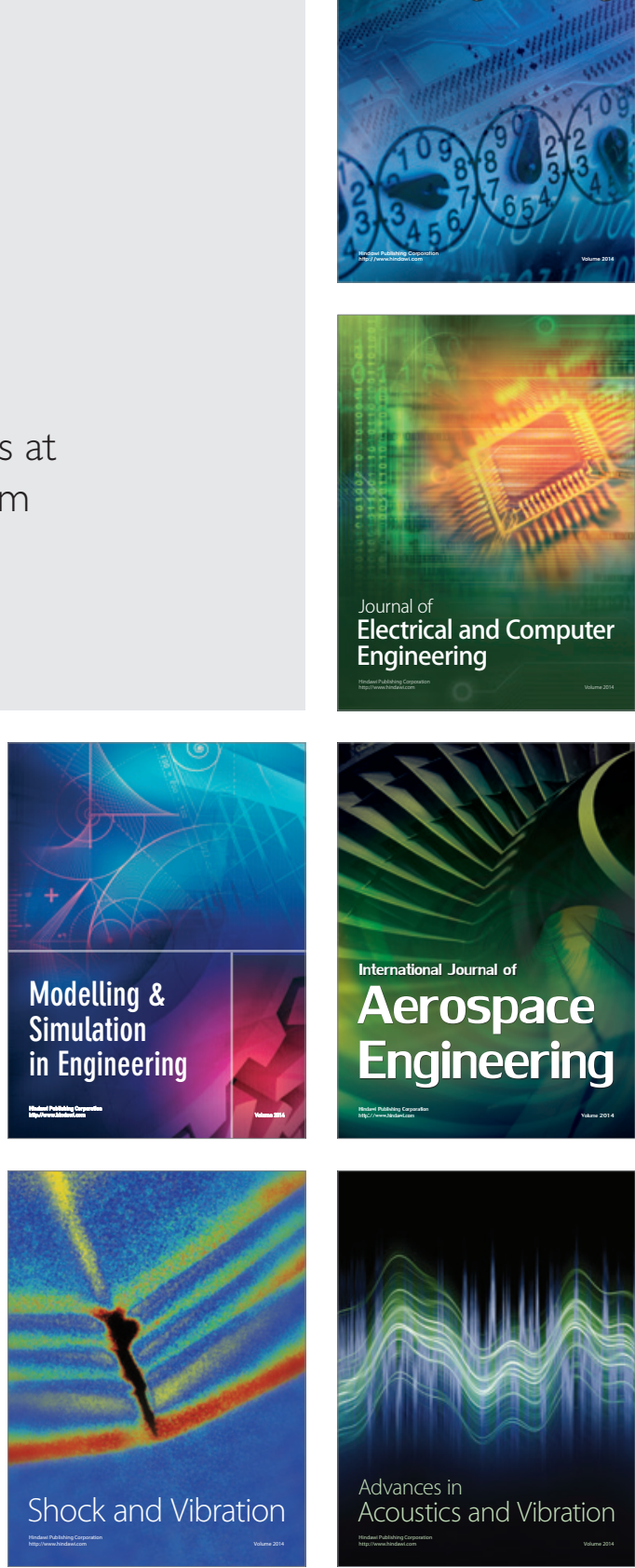